\title{
Da membrana ao núcleo: mecanismos moleculares de armazenamento da memória*
}

\author{
From membrane to nucleus: molecular \\ mechanisms of memory storage
}

Benilson Souza Nunes ${ }^{1}$ Paulo Roberto Queiroz ${ }^{2}$

\section{Resumo}

Os estudos relacionados ao armazenamento de memória têm apresentado notáveis avanços em sua abordagem molecular. Enzimas chaves desse processo, tais como a proteína cinase A (PKA) e a proteína cinase C (PKC), bem como fatores de transcrição como a CREB-1 e a CREB2, participam da plasticidade neuronal de consolidação da memória. A bibliografia deste trabalho conta com alguns dos mais avançados estudos relacionados à transdução de sinal em circuitos neuronais simples. As pesquisas se pautam em duas modalidades de armazenamento convencionadas: facilitação de curta duração (STF) e facilitação de longa duração (LTF), cada uma apresentando seus mecanismos particulares. A facilitação de duração média (ITF) também é mencionada. O objetivo do trabalho, portanto, é o de apresentar, de maneira sistemática, a cadeia de eventos moleculares e celulares que acompanham o armazenamento da memória implícita em suas diferentes durações. Em conclusão, os avanços da biologia molecular prometem fornecer perspectivas cada vez mais íntimas dos mecanismos que governam as funções mentais, especialmente a memória.

Palavras-chave: AMPc. PKA. CREB. Transcrição. Plasticidade sináptica. Aplysia.

\section{Abstract}

The studies related to memory storage have being noticing advances at the molecular issue. Key enzymes of this process, such as protein kinase $\mathrm{A}(\mathrm{PKA})$ and protein kinase $\mathrm{C}$ (PKC), as well as transcription factors like CREB-1 and CREB-2, participate of the neuronal plasticity of memory consolidation. The bibliography of the present study count with some of the most advanced studies related to sign transduction into simple neuronal circuits. The studies are guided in two modes of storage: short-term facilitation (STF) and long-term facilitation (LTF), each one presenting particular mechanisms. Intermediate-term facilitation (ITF) is also mentioned. This study, therefore, is to present, on a systematic perspective, the molecular and cellular chains events that underlie the storage of implicit memory at different stages. To conclude, the advances in molecular biology are promising to provide intimate approaches of the mechanisms that govern our mental functions, especially memory.

Keywords: AMPc. PKA. CREB. Transcription. Synaptic plasticity. Aplysia. 


\section{Introdução}

O campo das neurociências tem se mostrado revelador nos últimos anos. Pesquisas moleculares deram início a diversas discussões a respeito dos mecanismos que correspondem, ou deveriam corresponder, aos processos mentais. Em geral, as pesquisas que tratam do funcionamento molecular no cérebro buscam, em grande parte, elucidações que contribuirão para o tratamento de determinadas patologias neurológicas como o Alzheimer, Parkinson e a fibromialgia (MATSUDA et al., 2010). Contudo, nessa tentativa de elaborar novos tratamentos, e com a aceleração concomitante do avanço biotecnológico, uma nova perspectiva de estudo se apresentou, abrindo novos caminhos para o velho e importante debate que pretende superar o antigo dualismo entre "mente e cérebro" (RUSSO; PONCIANO, 2002).

A corrida pelo entendimento dos mecanismos últimos que governam o cérebro tem adotado, cada vez mais, uma abordagem materialista e naturalizante (RUSSO; PONCIANO, 2002), buscando se fundar em fatos de ordem bioquímica - como as cascatas enzimáticas disparadas a partir de receptores de membrana nos neurônios. Dessa forma, a contínua edificação de conhecimentos relacionados, bem como o desenvolvimento tecnológico envolvido nessas investigações, contribui para o desenvolvimento de uma nova ciência que poderia se chamar Psicologia Molecular (MOURA; COSTA, 2012) ou, ainda, Biologia Molecular da Cognição (SQUIRE; KANDEL, 2003), e que será abordada no presente artigo. Contudo, segundo uma linha de investigação mais específica dessa área, ou seja, os mecanismos moleculares de consolidação da memória.

$\mathrm{O}$ antigo dualismo cartesiano entre mente e corpo parece se tornar cada vez mais antiquado, não se pensa mais em duas substâncias diferentes durante as investigações, mas em apenas uma, ou melhor, em apenas uma como produtora dos eventos mentais: fala-se de um substrato neural das funções mentais (SAKAGUCHI; HAYASHI, 2012). Assim, os cientistas de hoje encontram boas razões para acreditar que todas as atividades da mente emergem de uma parte especializada do nosso corpo, a saber, do encéfalo (SQUIRE; KANDEL, 2003). Essa abordagem biológica na qual se observa, consequentemente, determinismos biológicos marcantes (RUSSO; PONCIANO, 2002) oferece, todavia, uma perspectiva que acompanha recentes avanços biotecnológicos e novas tecnologias de neuroimagens, fornecendo um horizonte de investigação nunca antes imaginável.

A complexidade existente no funcionamento cerebral, contudo, pode apresentar barreiras metodológicas relevantes. Uma vez não sendo de simples execução observar in vivo muitos dos eventos moleculares, algumas limitações se impõem aos neurocientistas para compreender mecanismos microscopicamente ou mesmo em escala nanométrica. Entretanto, muito dos fundamentos de biologia molecular já oferecem princípios suficientes para deduções importantes a respeito do assunto como a sequência de eventos envolvidos na regulação da expressão gênica em processos neuronais, tema hoje recorrente nas neurociências. Sabe-se, por exemplo, que a desregulação da expressão de microRNAs (miRNA) pode estar associada a disfunções neurológicas importantes, tal como o Alzheimer (FAGHIHI et al., 2010), tornando possível, inclusive, a prévia quantificação sérica de determinado micro-RNA envolvido nessa doença (LEIDINGER et al., 2013).

São inúmeras as pesquisas que, buscando elucidar fisiopatologias, causas e consequências associadas que acabam por, secundariamente, levantar informações pertinentes à neurociência em sua abordagem desinteressada (do ponto de vista terapêutico), isto é, uma neurociência que tem como objetivo primeiro não o desenvolvimento de novos tratamentos - apesar de sempre contribuir nisso - , mas o seu próprio desenvolvimento. É comum cientistas chamarem essas oportunidades de "janelas". Deriziotis e Fisher (2013) abordaram distúrbios genéticos da linguagem afirmando que, embora mutações no gene FOXP2, um gene relacionado à linguagem, sejam raras, esse gene fornece uma valiosa "janela molecular" a respeito dos mecanismos neurogenéticos da linguagem humana falada.

Ainda que o objetivo de determinadas pesquisas esteja relacionado, em primeiro nível, à determinada doença do cérebro, a ocasião permite fornecer, além de novos tratamentos e diagnósticos, um meio profícuo de solucionar pelo menos alguns dos mistérios que habitam o cérebro. A partir de ocasiões patológicas, portanto, a edificação das neurociências encontra sua contribuição mais valiosa.

Os estudos sobre a memória não foram exceções nessas janelas patológicas. São conhecidos importantes trabalhos relacionados aos seus mecanismos que possuem, como gatilho e meio de investigação, pacientes 
que apresentam determinadas disfunções, em especial a amnésia. Com base em um estudo com um paciente apresentando uma lesão no lobo temporal encefálico que se pode, inicialmente, deduzir a importância dessa região com relação à memória humana (SAKAGUCHI; HAYASHI, 2012). A lesão desse paciente, relatada em 1957, foi ocasionada pela retirada de uma porção do lobo temporal e do hipocampo (onde se visava tratar uma epilepsia). Após a cirurgia terapêutica, no entanto, observaram-se manifestações amnésicas relacionadas à memória declarativa, isto é, à memória consciente, da qual passou, então, a estar associada ao hipocampo, e ao lobo temporal encefálico em sua porção medial, regiões agora concebidas como de extrema importância para esse tipo de memória (SQUIRE; KANDEL, 2003).

Atualmente, a neurociência possui sua independência investigativa. É razoável afirmar que, em tempos passados, muito se esperava por janelas patológicas oportunas para estudo. Contudo, hoje a neurociência é capaz de tomar sua própria iniciativa, formulando seus próprios problemas e modelos de estudo sem precisar esperar por ocasiões singulares de disfunções cognitivas. Essa nova tomada neurocientífica, que usufrui de importantes recursos tecnológicos, permite o desenvolvimento de trabalhos que outrora foram considerados inconcebíveis (LASHLEY, 1950).

Os estudos neurocientíficos das funções mentais já reservam um grande volume bibliográfico, sobretudo terapêutico. Contudo, faz-se oportuno realizar uma reunião mais ou menos sistemática do que já se tem em avanço a respeito dos seus mecanismos mais íntimos. Dessa forma, busca-se, no presente trabalho, portanto, o substrato neural (SAKAGUCHI; HAYASHI, 2012) das faculdades mentais, em especial da memória, que têm apresentado notáveis avanços em recentes estudos (BLISS; COLLINGRIDGE, 2013; SACKTOR, 2012; SANHUEZA; LISMAN, 2013; TULLY; BOLSHAKOV, 2010).

O conteúdo desse texto busca, inicialmente, elucidar alguns dos mecanismos básicos de sinalização celular que envolvem cascatas enzimáticas específicas na fisiologia neuronal. Assim, serão expostos, tendo como plano de fundo a memória, alguns dos processos moleculares envolvidos na plasticidade do sistema nervoso, por exemplo, os eventos bioquímicos que transcorrem durante a formação de novos terminais sinápticos. Os estudos apresentados se baseiam, sobretudo, em sistemas orgânicos mais simples do ponto de vista evolutivo, tal como a Aplysia (um caramujo marinho), Drosophila (BLUM et al., 2009) e pequenos mamíferos (JOSSELYN et al., 2001). Contudo, não se deve descartar que os processos neurais descobertos por meio desses estudos não se encontrem, também, em mamíferos superiores, tal como o homem. A evolução guarda um princípio de conservação (SQUIRE; KANDEL, 2003) marcante ao longo dos tempos, mantendo mecanismos celulares comuns entre as espécies.

A partir do exposto, o objetivo desse trabalho foi descrever os mecanismos moleculares básicos envolvidos em relação ao processo de formação da memória.

\section{Metodologia}

O Principles of Neural Science, uma volumosa e famosa bibliografia de capítulos sistematizados, oferece um ponto de partida interessante - e sólido - para a compreensão de mecanismos básicos.

Além do que já é fornecido no Principles of Neural Science, há uma bibliografia brasileira de renome intitulada "Cem Bilhões de Neurônios: Conceitos Fundamentais da Neurociência” na qual é possível encontrar uma linguagem, talvez, mais acessível, sobretudo no Brasil. Outras fontes fundamentais para o presente trabalho foram obtidas na biblioteca do Centro Universitário de Brasília (UniCEUB). A biblioteca oferece relativo volume bibliográfico neurocientífico, permitindo possível desenvolvimento de alguns estudos na área.

Quanto ao conteúdo especializado, a pesquisa se deu em bancos de dados online internacionais, tais como o Molecular Brain, um importante, porém, recente, banco de artigos a respeito de estudos moleculares. Outros bancos de dados, tais como Genome Biology, BMC Neuroscience, Journal of Molecular Signaling, Pharmacological Reviews, The Journal of Neuroscience e Neural Development oferecem uma segunda alternativa, apesar dos artigos pertinentes não se tratarem, sempre, de conteúdo especialmente molecular.

A seleção, bem como o critério de exclusão para a bibliografia, se deu da seguinte forma: artigos com objetivo terapêutico, mesmo que não tratassem, fundamentalmente, de mecanismos moleculares, foram incluídos. Também foram inclusos, obviamente, trabalhos relacionados, diretamente, à elucidação de processos moleculares. Palavras-chaves usadas na pesquisa incluíam "molecular", "neural”, "mechanisms", "signaling", "neurobiology”, “neuroscience”, "psychology”, "neuropsychology” e demais 
termos-chaves para a biologia molecular como "RNA", "transcription" e "expression".

Por fim, a ordem de preferência dos artigos levava em conta, principalmente, o seu volume de conteúdo molecular mais as suas respectivas correlações com funções mentais básicas. Trata-se, portanto, de um estudo que aborda duas ordens ontológicas, ainda que seu alvo principal esteja focado na dimensão dos processos celulares e bioquímicos.

\section{Desenvolvimento}

\subsection{Da membrana ao citoplasma: a transdução de sinal}

Os mecanismos moleculares dos neurônios, e do cérebro como um todo, guardam semelhanças muito próximas a outras células do nosso organismo. Muitos cientistas esperavam encontrar tipos exclusivos de moléculas, tais como determinadas classes de proteínas, exclusivas do cérebro. Contudo, sabe-se hoje que toda a matéria viva possui substratos comuns, incluindo nossos pensamentos e lembranças (KANDEL, 2009). São encaminhamentos diferentes dessas moléculas (também presentes em outros tecidos), portanto, que devem ser investigados, a fim de desvendar quais alterações específicas são produzidas em nosso cérebro. O somatório dessas alterações produzidas, capazes de conferir novas conjunturas químicas e estruturais, denominou-se, por fim, engrama (SAKAGUCHI; HAYASHI, 2012; SQUIRE; KANDEL, 2003).

Lashley (1950), em sua produção denominada In Search of the Engram, acreditou que o engrama da memória permaneceria um mistério (SÁ; MEDALHA, 2001). Frente às limitações tecnológicas da época, Lashley não parecia otimista com a possibilidade de conceber um mecanismo capaz de satisfazer a ideia de um traço fisiológico para a memória. Sabe-se hoje, no entanto, por meio de novos modelos de investigação e tecnologias de imagem, que os traços fisiológicos da memória, e das funções mentais como um todo pode, finalmente, ser estudado com o rigor metodológico adequado. Tendo à disposição novas oportunidades de investigação, a comunidade neurocientífica, desde os anos 90, em que, nos Estados Unidos foi declarada a "década do cérebro" (RUSSO; PONCIANO, 2002), iniciou uma corrida para desvendar o código neurobiológico da mente, tal como se procedeu com a corrida para o sequenciamento do ge- o século do código genético; o século XXI se apresenta, dessa vez, como o século das neurociências (KANDEL, 2009; SQUIRE; KANDEL, 2003).

Alguns mecanismos neurobiológicos das funções mentais já estão a caminho de uma elucidação satisfatória. Parece não haver mais dúvidas que os processos metabólicos do cérebro possuem mecanismos comuns, isto é, possíveis de serem encontrados em outros tecidos e órgãos. Um desses mecanismos, a via do AMP cíclico (AMPc), uma via bioquímica de extrema importância para a plasticidade sináptica, não é exclusiva do sistema nervoso, sendo encontrada em processos metabólicos normais de outros tecidos, tal como o fígado, intestino e rins (SQUIRE; KANDEL, 2003). O que há de comum entre diferentes tecidos no uso da via do AMPc, portanto, é a necessidade de produzir mudanças metabólicas persistentes (KANDEL, 2009), isto é, que ultrapassam circunstâncias fisiológicas imediatas e passam a perdurar por minutos, horas ou dias. No caso dos neurônios, a via do AMPc produzirá mudanças sinápticas cruciais para a memória de curta duração e, em segunda instância, mudanças estruturais para a memória de longa duração.

A possibilidade de produzir alterações celulares duradouras no cérebro compactua com a adaptação inerente dos organismos vivos. Em resposta ao ambiente, portanto, é possível estabelecer mudanças físico-químicas capazes de atravessar longo período, alterando a maquinaria celular enzimática e alcançando, finalmente, a expressão genética da célula: tal é o conceito da plasticidade cerebral (BRANDÃO, 2004). Considerando-se essa abordagem bioquímica, é a partir de uma perspectiva reducionista, por fim, que serão abordados alguns dos mecanismos moleculares associados às funções mentais, a começar pelo sistema de segundos mensageiros.

\subsubsection{Receptores de Membrana e Segundos Mensage- iros: o início da neuromodulação}

O sistema de segundos mensageiros e suas decorrências bioquímicas no interior celular constituem a chave para compreender os mecanismos de neuromodulação e plasticidade sináptica para a memória. Sabe-se que uma das funções da transmissão sináptica é a de produzir um potencial de ação no terminal pós-sináptico do neurônio adjacente (LENT, 2010), propagando informação ao longo das fibras nervosas. Contudo, um segundo mecanismo central se faz presente nos processos neuronais de sinapse. Nem sempre a transmissão sináptica irá produzir, necessariamente, um rápido potencial de ação, pode 
ser que os eventos que sucedem a transmissão sináptica sirvam para uma neuromodulação, isto é, sirva para que a célula adjacente efetue cascatas enzimáticas específicas, resultando em alterações prolongadas da célula e de suas conexões (SÁ; MEDALHA, 2001), caracterizando o que se chama de plasticidade sináptica (LENT, 2010).

O mecanismo mais conhecido desse processo, e provavelmente o mais primitivo, é a via do AMPc. Esse segundo mensageiro pode ser encontrado até mesmo em bactérias como a Escherichia coli (KANDEL, 2009). Contudo, apesar de se tratar de um segundo mensageiro tão primitivo, ele guarda funções críticas na plasticidade cerebral de organismos superiores. Uma vez reconhecido um neurotransmissor na superfície celular por meio de um receptor, moléculas vizinhas na membrana celular são ativadas (LENT, 2010). Estas, por sua vez, ativam uma modalidade enzimática capaz de produzir um segundo sinal. No caso do AMPc, ele é produzido a partir de moléculas de ATP no ambiente intracelular, por meio da enzima adenilato ciclase previamente ativada por uma proteína transdutora (KANDEL, 2012; LENT, 2010; SQUIRE; KANDEL, 2003).

Deve-se entender os segundos mensageiros, que são desencadeados pelos primeiros mensageiros (os neurotransmissores) (LENT, 2010), como um sinal traduzido do meio extracelular. A tradução desses sinais, compreendida aqui como transdução, é efetuada por uma molécula transdutora específica, a proteína G (KANDEL et al., 2003). A proteína $G$ nesse processo tem uma função mediadora entre o receptor (que recebe o sinal extracelular) e a enzima que irá produzir o segundo mensageiro.

Os receptores responsáveis pelo início da transdução são chamados receptores metabotrópicos (SQUIRE; KANDEL, 2003). Diferem dos receptores chamados ionotrópicos por não serem, eles próprios, canais iônicos. Em vez disso, por meio de uma sequência de eventos moleculares, eles atuam sobre canais iônicos vizinhos (LENT, 2010) ou, no caso que se aplica a esse trabalho, sobre proteínas transdutoras (tal como a proteína $\mathrm{G}$ ), capazes de ativar uma enzima. A enzima em questão é uma ciclase (a adenilato ciclase) que, por sua vez, produz o AMPc a partir de ATP intracelular. O AMPc, então, se liga a regiões ativadoras de enzimas cinases (enzimas que fosforilam outras proteínas) (SKÅLHEGG; TASKEN, 2000), permitindo que estas ativem ou desativem canais ou, em outro momento, ativem fatores de transcrição tal como a Proteína Ligadora do Elemento Responsivo ao
AMPc (CREB), responsável por mudanças celulares importantes no neurônio a partir da síntese de novas proteínas (NESTLER; MALENKA, 2004).

Essa complexa cadeia de eventos se dá da seguinte forma: primeiramente, o terminal pré-sináptico de um neurônio precisa liberar, na fenda sináptica, o neurotransmissor em questão. Por exemplo, para a consequente ativação da adenilato ciclase, os neurotransmissores serotonina, dopamina ou noradrenalina (IZQUIERDO et al., 2003), atuando sobre receptores na superfície celular, são capazes de desencadear o aumento do AMPc no lado interno da célula. Assim, uma vez que o neurotransmissor tenha alcançado um receptor metabotrópico correspondente no terminal pós-sináptico (existe mais de um receptor para o mesmo neurotransmissor), uma nova conformação se produzirá no receptor, expondo sua região de ligação com a proteína G (LENT, 2010). Esses receptores que atuam sobre a proteína transdutora (a proteína $\mathrm{G}$ ) recebem o nome de receptores acoplados à proteína G (GPCR) e atuam separando a subunidade $a$ dessa proteína das suas outras duas subunidades, a subunidade $\beta$ e $\gamma$ (MOURA, 2011), que permanecem acopladas ao receptor.

Mais de um tipo de proteína $\mathrm{G}$ foi catalogado, variando conforme a estrutura e sequência de aminoácidos da sua subunidade a (MOURA, 2011). Há, por exemplo, a proteína $G_{s}$ estimuladora, e a proteína $G_{i}$, inibitória (KANDEL et al., 2003). Contudo, para a abordagem da sequência de eventos capazes de produzir a plasticidade sináptica relativa à memória, o foco será dado, apena, à proteína ativadora $G_{s}$ que atuará ativando uma ciclase, com o consequente aumento de AMPc intracelular.

$\mathrm{Na}$ presença de um neurotransmissor ou neuromodulador ligado ao GPCR, uma ação se dá na subunidade a da proteína $G$, fazendo com que a molécula de GDP (daí o seu nome - proteína G) presente na estrutura inativa dessa subunidade se desligue e uma molécula de GTP tome o seu lugar liberando, nessa reação, a subunidade a das outras duas subunidades (LENT, 2010; MOURA, 2011). A subunidade $\alpha$, então, está livre para flutuar na bicamada lipídica da membrana e se ligar, finalmente, à uma enzima efetora capaz de transformar ATP em AMPc, o segundo mensageiro. Um complexo entre a subunidade $a$ da proteína $\mathrm{G}$ e a adenilato ciclase deverá, então, se formar, resultando em um aumento substancial do AMPc intracelular (MOURA, 2011).

O AMPc, gerado com base na ativação da adeni- 
lato ciclase pela subunidade $a$ da proteína $G_{s}$ não encerra a cadeia em cascata capaz de produzir efeitos duradouros no neurônio. Outra molécula com atividade enzimática precisará entrar em cena para efetuar mecanismos celulares importantes. Essa nova molécula é a proteína cinase dependente de AMPc (PKA), capaz de adicionar grupos fosfatos tanto em canais iônicos (abrindo-os ou fechando-os) quanto em fatores de transcrição-chaves para mudanças estruturais no neurônio (SQUIRE; KANDEL, 2003; KANDEL, 2012). Para tanto, o AMPc intracelular residual, que foi aumentado, substancialmente, pela adenilato ciclase, liga-se às subunidades reguladoras da PKA, liberando suas subunidades catalíticas com real poder de fosforilação nos resíduos de serina e treonina em proteínas-alvo (SKÅLHEGG; TASKEN, 2000).

É importante ressaltar que os mecanismos até agora descritos estão, todavia, imersos em um nível de complexidade consideravelmente maior. A descrição do processo de consolidação neste trabalho está restrita, relativamente, a poucas moléculas, visando a melhor compreensão inicial do assunto. Contudo, sabe-se que os receptores metabotrópicos variam em grande número, de acordo com o neurotransmissor ligante e com os seus efeitos adjacentes na membrana celular (LENT, 2010). Sabe-se, inclusive, que, nos mecanismos da memória, outras vias em cascata ocorrem, concomitantemente, à do AMPc-PKA. Na evocação da memória, bem como em determinados mecanismos de consolidação, por exemplo, há a participação simultânea de outra via, a via da cinase regulada por sinal extracelular (ERK) (IZQUIERDO et al., 2003; 2006). Sendo assim, vale alertar que diversos outros processos concomitantes, além dos descritos, acompanham a formação da plasticidade sináptica na aquisição de memória.

\subsubsection{A Memória de Curta Duração depende da via do $A M P C$}

Lent (2010), em sua obra central intitulada “Cem bilhões de neurônios: conceitos fundamentais da neurociência”, afirma que a plasticidade sináptica é atualmente considerada uma propriedade universal dos sistemas nervosos, representando a base material da memória. A razoabilidade dessa afirmação encontra sua fundamentação nos estudos desenvolvidos no último século utilizando sistemas neuronais simples, como o da Aplysia, um caramujo marinho modelo para as investigações a respeito da memória. Nessas pesquisas descobriu-se que existem, basicamente, cinco tipos de armazenamento de memória para arranjos neuronais simples, são eles a habituação, a desabituação, a sensibilização, o condicionamento clássico e o condicionamento operante (KANDEL, 2012).

Para tornar possível uma abordagem didática, será feita a análise, mais restritamente, na aprendizagem por sensibilização, pois ela é o gatilho necessário para a compreensão dos tipos de memória mais complexas, tal como a memória de longa duração, que envolve mecanismos responsáveis por mudanças nos arranjos terminais do neurônio, conferindo um armazenamento efetivamente prolongado. Também é importante mencionar que o mecanismo descrito a seguir diz respeito à memória implícita, que se distingue da memória explícita (ou declarativa), por se caracterizar inconsciente (BRANDÃO, 2004; IZQUIERDO et al., 2003; LENT, 2010; SÁ; MEDALHA, 2001; SQUIRE; KANDEL, 2003). Esse tipo de memória fica impresso na maquinaria neuronal sem necessariamente se apresentar à consciência como no caso de memórias de fatos e eventos passados. Assim, a memória implícita, não declarativa, se trata da memória de contextos motores, exemplificada no conjunto de movimentos realizados para andar de bicicleta (SQUIRE; KANDEL, 2003), em que não há necessidade de trazer à consciência os vários passos motores necessários para realizar essa tarefa: simplesmente o ato é realizado "automaticamente".

No modelo de estudo para a memória por sensibilização da Aplysia, um choque é aplicado à sua cauda, a fim de produzir um movimento reflexo vigoroso. A princípio, haveria de ocorrer sensibilização, apenas, entre o neurônio sensorial (que identifica o choque) e o neurônio motor (que promove a retração da cauda), tal como no modelo de estudo de retração da brânquia para a habituação. Contudo, as pesquisas revelaram um princípio diferente entre a memória por habituação e a memória por sensibilização. O primeiro caso, a memória por habituação, é caracterizada por ser homossináptica, isto é, resulta de uma mudança na atividade da mesma via que é excitada pelo estímulo que produz o reflexo (SQUIRE; KANDEL, 2003). A memória por sensibilização, contudo, é heterossináptica (SÁ; MEDALHA, 2001), ou seja, ela provoca uma mudança no neurônio sensorial e motor da via estimulada e, além destes, provoca mudanças em interneurônios que modulam os reflexos da brânquia (KANDEL, 2009). Logo, na sensibilização, diferentemente da habituação, há um reflexo generalizado envolvendo tanto a retração da cauda quanto da brânquia, caracterizando um aumento na intensidade do reflexo. 
Após o choque na cauda, qualquer pequeno estímulo (mesmo na brânquia) produzirá uma reação mais vigorosa que o normal, típico da sensibilização. Esse fenômeno se assemelha ao caso do susto evocado com o som de um tiro, em que qualquer pequeno barulho seguido do tiro produzirá reações ou espantos que não ocorreriam se não houvesse escutado o tiro antes (SQUIRE; KANDEL, 2003). Nessa ocasião, assim como na Aplysia, os sentidos ficam em uma espécie de prontidão (estado de vigília). Diz-se, portanto, que se atingiu o estado de sensibilização. Em contraste, a habituação resulta de estímulos menos intensos, porém, constantes, tal como, no ruído gerado por máquinas de uma fábrica. Nesse exemplo, o ruído das máquinas chama a atenção nas primeiras horas, porém, com o passar do tempo, esse mesmo ruído se torna quase imperceptível ou, simplesmente, não chama mais a atenção. Dessa forma, observa-se que o indivíduo está habituado ao estímulo.

A chave para a compreensão da reação motora intensificada na sensibilização se encontra nos interneurônios modulatórios (KANDEL, 2009). Esses neurônios, situados entre o neurônio sensorial e o neurônio motor, são capazes de modular a transmissão sináptica do neurônio sensorial ao neurônio motor. Para tanto, o interneurônio realiza um processo chamado de facilitação heterossináptica (BRANDÃO, 2004), em que, no modelo de estudo da aplísia, ele intensificará a liberação de neurotransmissores pelo neurônio sensorial (KANDEL, 2002), aumentando a resposta do neurônio motor. O neurônio sensorial, por sua vez, usa o neurotransmissor glutamato para se comunicar com o neurônio motor (HAWKINS et al., 2006), levando à formação de um novo potencial sináptico no neurônio motor para a retração da cauda ou da brânquia.

A conexão entre o interneurônio modulatório e o neurônio sensorial é do tipo axoaxônica (LENT, 2010; SQUIRE; KANDEL, 2003), isto é, o terminal pré-sináptico do interneurônio se conecta ao neurônio sensorial em sua porção distal do axônio, próximo aos terminais sinápticos do neurônio sensorial que estabelecem contato com o neurônio motor. A localização dessa interação sináptica é muito importante, uma vez que ela está próxima de onde os neurotransmissores do neurônio sensorial serão liberados. Logo, essa interação sináptica será capaz de agir, diretamente, na liberação de transmissores por parte do neurônio sensorial, sendo o mecanismo pelo qual a memória por sensibilização de curto prazo se dará.
No terminal pós-sináptico do neurônio sensorial (na porção distal do axônio), em que se mantém a sinapse com o interneurônio modulatório, se encontram receptores serotoninérgicos responsáveis pelo desencadeamento dos segundos mensageiros da memória de curto prazo na sensibilização (HAWKINS et al., 2006). Com o choque na cauda da aplísia, os interneurônios irão, então, liberar serotonina com função modulatória que, por sua vez, se ligará em receptores correspondentes na membrana do neurônio sensorial. Esse processo ativará a proteína $G_{s}$ acoplada ao receptor serotoninérgico. A porção $a$ da proteína $G_{\mathrm{s}}$ então, se separa das outras duas subunidades ( $\beta$ e $\gamma$ ) e se difunde pela membrana plasmática, até encontrar o sítio de ligação com a enzima efetora adenilato ciclase. Somente após a formação do complexo da subunidade a da proteína $\mathrm{G}_{\mathrm{s}}$ com a adenilato ciclase é que se dará a síntese de AMPc, o segundo mensageiro em questão (MOURA, 2011)

O aumento do AMPc intracelular leva a uma série de eventos que culminará em uma plasticidade sináptica do neurônio, aumentando a intensidade de ligação entre o neurônio sensorial e o neurônio motor (HAWKINS et al., 2006). Esse processo, que envolve receptores metabotrópicos, é mais lento quando comparado a outras reações sinápticas, conferindo mudanças neuromodulatórias que persistem por mais tempo (LENT, 2010). Seguindo esse princípio, portanto, é possível compreender a memória de curta duração, que constitui mudanças na maquinaria bioquímica do neurônio capaz de modular a atividade sináptica intensificando-a - por meio de um mecanismo facilitatório desencadeado pelo interneurônio - ou deprimindo-a, como no mecanismo homossináptico de habituação.

\subsubsection{OAMPc e a Via do Fosfoinositol Ativam Proteínas Cinases Modulatórias}

Com a ação da adenilato ciclase sobre o ATP intracelular, o AMPc sofre aumento substancial (MOURA, 2011). Essa ocasião é o motor necessário para ativação de uma segunda molécula nessa cadeia de eventos: a proteína cinase dependente de AMPc (PKA) (KANDEL, 2012; MOURA, 2011; SKÅLHEGG; TASKEN, 2000). Essa enzima, capaz de fosforilar outras proteínas, possui duas subunidades regulatórias que, quando ligadas com o AMPc, liberam as duas outras subunidades catalíticas com poder enzimático efetivo. Logo, a PKA atuará sobre canais iônicos específicos, tais como duas classes especiais de canais de potássio (SÁ; MEDALHA, 2001) que irão se fechar 
após a adição de grupamentos fosfatos pela PKA. Como resultado, há uma redução na fase de repolarização do potencial de ação, prolongando-a. Concomitantemente ao impedimento do efluxo de potássio, canais de cálcio se abrem, permitindo o influxo deste, desencadeando, portanto, a liberação de mais neurotransmissores na fenda sináptica entre o neurônio sensorial e o neurônio motor em um segundo estímulo (KANDEL, 2002). Esses eventos, como o fechamento de canais de potássio, contribuem para a excitabilidade do neurônio (HAWKINS et al., 2006), mecanismo crucial para que ocorra a sensibilização.

O segundo mecanismo pelo qual a PKA age modulando a excitabilidade do neurônio ocorre por meio da sua ação em proteínas contidas nas vesículas sinápticas (THAKUR et al., 2004). Com mais vesículas ancoradas no sítio de liberação, mais neurotransmissores serão liberados do neurônio sensorial para o neurônio motor, aumentando, por fim, o nível de reação ao estímulo aplicado à cauda ou brânquia da Aplysia.

Em resumo, todos esses mecanismos convergem em uma finalidade comum, qual seja, deixar o neurônio sensorial previamente despolarizado (mas não o suficiente para liberar os neurotransmissores) além de preparar, com antecedência, mais vesículas para serem liberadas nos sítios ativos do neurônio pré-sináptico. Assim, quando o potencial de ação chegar ao terminal sináptico, uma maior quantidade de neurotransmissores será liberada para o neurônio motor, aumentando, significativamente, a reação comportamental observada, conforme o mecanismo de sensibilização na memória de curto prazo. Todos esses eventos facilitatórios ocorrem graças ao interneurônio modulatório que, com a liberação de serotonina na conexão axônica com o neurônio sensorial, possibilita que a sinapse entre o neurônio sensorial e motor se torne mais significativa para a reação ao estímulo.

A via do AMPc/PKA, contudo, não é exclusiva nesse processo. Uma outra reação em cascata desencadeada por neurotransmissores do interneurônio transcorre em paralelo para a memória de curta duração. Essa nova via de mensageiros possui como elemento transdutor a proteína $\mathrm{G}_{\mathrm{q}}$, que, também, é ativada por um receptor serotoninérgico (KANDEL, 2002). Com a ação do interneurônio modulatório, a proteína $\mathrm{G}_{\mathrm{q}}$ libera a sua subunidade capaz de ativar uma enzima que produz os segundos mensageiros dessa via: o diacilglicerol (DAG) e o trifosfato de inositol ( IP $_{3}$ ) (LENT, 2010; MOURA, 2011;
ROBERSON et al., 1999). A enzima efetora em questão, equivalente a adenilato ciclase, é a fosfolipase C (PLC), que produz não um, mas dois segundos mensageiros, usando como substrato uma molécula da própria membrana, o fosfatidil inositol 4,5 bifosfato, ou simplesmente fosfoinositol (PIP 2 ) (KANDEL et al., 2003; LENT, 2010). Enquanto o DAG resultante da quebra do $\mathrm{PIP}_{2}$ permanece na membrana aguardando a sua molécula ligante, o $\mathrm{IP}_{3}$, por ser hidrossolúvel (MOURA, 2011), se desloca citoplasma adentro, até encontrar o retículo endoplasmático, no qual irá solicitar, por meio de receptores na superfície do retículo, a liberação de cálcio no citoplasma da célula (MOURA, 2011).

O DAG, sendo hidrofóbico, permanece na membrana celular aguardando seu substrato, a proteína cinase C (PKC) (KANDEL et al., 2003; LENT, 2010). A maioria dos alvos da $\mathrm{PKC}$ estão relacionados ao metabolismo neuronal (LENT, 2010), apesar de, ainda, cumprir um papel na memória de curto prazo com função semelhante a da PKA (abertura de canais de cálcio e vesículas sinápticas). Dessa forma, as enzimas PKA e PKC, ambas, atuam sensibilizando o neurônio sensorial, isto é, facilitando a transmissão sináptica para o neurônio motor.

Os modelos de estudo com a Aplysia foram, em um segundo momento, transferidos para pesquisas in $v i$ tro. Nesses modelos, que usava um meio de cultura para neurônios, o choque na cauda da Aplysia foi substituído por injeções de serotonina na porção distal do axônio do neurônio sensorial (SQUIRE; KANDEL, 2003; KANDEL, 2009). Diversos estudos demonstram que esse modelo reproduz o que é observado, também, nos estímulos aplicados à Aplysia (HAWKINS et al., 2006). Trata-se, então, de um sistema simplificado usando uma via homossináptica, ou seja, um neurônio sensorial com seus terminais axônicos ligando em regiões pós-sinápticas de um neurônio motor. O interneurônio nesse caso é simulado com aplicações diretas de serotonina no neurônio sensorial (HAWKINS et al., 2006). Esse modelo de pesquisa passou a apresentar descobertas importantes como a memória de média duração, ou facilitação de tempo médio (em inglês, intermediate-term facilitation - ITF) (SUTTON et al., 2004). Nesse mecanismo, infusões consecutivas de serotonina no neurônio sensorial provocavam reações intracelulares novas: a célula passava a traduzir determinados RNAs mensageiros, ocasionando a síntese de novas proteínas, tendo como resultado, ao longo da cadeia de eventos, uma memória de maior duração (HAWKINS et 
al, 2006; SUTTON et al., 2004; SUTTON; CAREW, 2002).

A memória de curta duração envolve segundos mensageiros como o AMPc, capaz de ativar proteínas cinases responsáveis por mudanças na plasticidade sináptica, em especial atuando em proteínas que regulam a liberação de neurotransmissores e em canais iônicos. Já a memória de média duração envolve, além dos eventos observados na memória de curto prazo, a síntese de proteínas (mas não a transcrição de novos RNA's mensageiros). O próximo passo consiste em investigar os mecanismos da memória de longa duração, em que uma nova cadeia de eventos resultará em mudanças estruturais na célula neuronal, aumentando o número de conexões sinápticas (HAWKINS et al., 2006; SQUIRE; KANDEL, 2003).

\subsection{Do citoplasma ao núcleo: a transcrição de ge- nes para a memória de longa duração}

Uma das maneiras possíveis de distinguir as memórias de longa e curta duração é se baseando no fato de que a memória de longa duração envolve a expressão gênica do neurônio, solicitando a transcrição de genes relacionados às mudanças estruturais do terminal sináptico (HAWKINS et al, 2006; KANDEL, 2002; 2012). A descoberta de que a PKA se desloca para o núcleo trouxe uma nova perspectiva a respeito da transmissão sináptica (SQUIRE; KANDEL, 2003). Esse fato resultou em estudos intrigantes a respeito de quais genes, vias de segundos mensageiros e fatores de transcrição estariam envolvidos nesse processo.

A memória de longa duração pode, também, ser chamada de facilitação de longo prazo (LTF), assim como a memória de curta duração, que pode ser chamada de facilitação de curto prazo (STF). O fator de transcrição central observado na LTF é a proteína ligante do elemento responsivo ao AMPc-1 (CREB-1) (HAWKINS et al., 2006; JOSSELYN et al., 2001; KANDEL, 2012; SILVA et al., 1998). Essa proteína possui, ainda, uma forma inibitória, impedindo sua ação normal como fator de transcrição e contrabalanceando, portanto, o saldo final de alterações necessárias para a LTF. Essa proteína em questão se chama CREB-2 (KANDEL, 2012; SILVA et al., 1998) e é ativada pela proteína cinase ativada por mitógeno (MAPK). Além destas, outras proteínas irão compor o cenário de reações que produzirão mudanças estruturais (KANDEL, 2002), isto é, promoverão o crescimento de novas conexões sinápticas entre o neurônio sensorial e o neurônio motor.

\subsubsection{A Ativação da CREB-1 e CREB-2 Dependem de Enzimas Cinases}

Com os estudos do armazenamento sendo realizados in vitro, tornou-se possível um maior controle na quantidade de estímulo a ser aplicado no neurônio sensorial. Usando um único pulso de serotonina na região distal do axônio do neurônio sensorial, uma STF se desenvolve. Contudo, ao aplicar cinco pulsos de serotonina, outra cadeia de eventos tem início, resultando em uma LTF (HAWKINS et al., 2006; KANDEL, 2002; SQUIRE; KANDEL, 2003).

A enzima PKA, presente também na formação da memória de curto prazo, fará importante papel na LTF. Sabe-se que a PKA atua ativando enzimas por meio da fosforilação de resíduos de serina e treonina em proteínas chaves do processo de armazenamento. Os canais iônicos e proteínas envolvidas na exocitose de neurotransmissores já foram citadas na STF. Dessa vez, a PKA (bem como a PKC e outras cinases), atuará fosforilando proteínas que irão agir como fatores de transcrição. $\mathrm{O}$ alvo mais importante na LTF para as cinases é a CREB-1, o fator de transcrição responsável por se ligar em uma região promotora chamada elemento responsivo ao AMPc (CRE) (KANDEL, 2012; JOSSELYN et al., 2002).

Uma série de cinases, além da PKA, já foram descritas como sendo potenciais ativadoras da CREB-1 (e também da sua isoforma que será descrita adiante). Exemplos de cinases que atuam fosforilando a CREB são a PKC, a proteína cinase dependente de cálcio calmodulina (CaMK's) e a proteína cinase ativada por mitógeno MAPK (JOSSELYN et al., 2002; KANDEL, 2012; MONTMINY, 1997; SILVA et al., 1998), todas elas influenciando a transcrição de novos genes via ativação/inativação da CREB. Todos esses mecanismos possuem um início comum que é o aumento do AMPc intracelular. Enquanto na STF o aumento de AMPc é suficiente, apenas, para fortalecer a interação sináptica já existente, na LTF as cinases ativadas pelo AMPc são capazes de alcançar o núcleo e desencadear a síntese de RNA's mensageiros (RNAm), com consequente síntese de novas proteínas.

A CREB-1, contudo, possui sua isoforma inibidora, a CREB-2 (HAWKINS et al., 2006; KANDEL, 2002, 2012), que necessita de mecanismos inativadores para que a ação da CREB-1 tenha efeito. Sua inativação dependerá da via MAPK (SHARMA; CAREW, 2004), uma família de cinases importantes para que a LTF se desenvolva. Estudos com a Aplysia mostraram que, havendo 
supressão da CREB-2, um único pulso de serotonina no neurônio sensorial já é capaz de produzir os efeitos da memória de longo prazo, sem ser necessário segundos pulsos do neurotransmissor (HAWKINS et al., 2006). Os efeitos observáveis da ação da CREB-1 com a supressão da CREB-2 incluem o crescimento de novas conexões sinápticas (KANDEL, 2012). Tudo isso com apenas um único pulso de serotonina que devia, em condições normais, apenas desencadear a memória de curto prazo.

Sabe-se que os efeitos celulares e moleculares da ativação da CREB são bastante amplos, envolvendo um grande número de moléculas. Uma curiosidade com respeito a CREB se dá em pesquisas relacionadas ao uso de drogas. A CREB, e uma outra molécula, a delta-fosB, possui participação central na tolerância e sensibilização à drogas, tais como a cocaína (NESTLER; MALENKA, 2004), contribuindo para o desejo insaciável do paciente acometido por vício.

\subsubsection{Ativando os Fatores de Transcrição da Memória de Longo Prazo}

Utilizando o sistema de ativação da PKA, a cadeia de eventos se desenrolará a partir do aumento de AMPc intracelular, induzido por repetidos pulsos de serotonina no neurônio sensorial (KANDEL, 2002). Uma vez ligado o AMPc nas subunidades reguladoras da PKA, as subunidades catalíticas desta são liberadas e se deslocam até o núcleo para fosforilar a CREB-1 (LEE et al., 2008). Acredita-se que, nesse meio caminho, a PKA fosforile outra cinase, a MAP cinase, ou MAPK, ativando-a. Por outro lado, se diz que a MAPK não tenha um sítio de fosforilação direta para a PKA. Todavia, sabe-se que há um sítio de fosforilação conhecido para a ERK (SHARMA; CAREW, 2004), uma enzima que se relaciona com a via que a MAPK participa. Seja como for, o aumento de AMPc celular que ultrapasse o aumento observado na STF (5 ou mais pulsos de serotonina) leva ao aumento de subunidades catalíticas da PKA se deslocando para o núcleo, com consequente ativação da CREB-1 (BAR et al., 1995; KANDEL, 2012).

Os mecanismos de ativação da MAPK por meio PKA são notavelmente complicados. Inúmeras outras moléculas participam desse processo em uma longa cadeia de eventos com ativações e desativações moleculares que envolvem, inclusive, outras cinases ativadas por segundos mensageiros, tal como a PKC. Uma explanação aprofundada do assunto pode ser encontrada nas referências bibliográficas (GERITS et al., 2008).
A MAPK, assim como a PKA, se desloca para o núcleo, com consequente desativação da CREB-2, permitindo a livre ação da CREB-1 (LEE et al., 2008). A LTF, portanto, exige diferentes vias moleculares para sua formação: paralelamente à ativação de determinadas proteínas, outras devem ser inativadas. Como bem observou Kandel (2012), a transição da memória de curta duração para a de longa duração exige a remoção simultânea de repressores transcricionais e ativação de fatores transcricionais. A CREB-2 não é a única molécula a ser inativada, algumas enzimas fosfatases, que fazem ação contrária às cinases, precisam, também, ser desativadas. Exemplos dessas enzimas são a proteína fosfatase 1 (PP1) e a calcineurina (HAWKINS et al., 2006).

As ações moleculares antagonistas desse processo, interpretou Kandel, servem para que experiências sensoriais que não são relevantes não alcancem os fatores de transcrição para a memória de longo prazo (KANDEL, 2009). Assim, uma sequência de choques com intervalos determinados na cauda da Aplysia (um estímulo forte repetido) promove a transcrição de genes responsáveis pelo crescimento de novas terminações sinápticas, enquanto, apenas, um leve estímulo (ou apenas um único impulso de serotonina in vitro) restringe a cascata de eventos à ação da PKA sobre canais iônicos e proteínas envolvidas na exocitose de neurotransmissores na fenda sináptica, levando a memória de curta duração.

\subsubsection{A CREB-1 Ativada Promove a Transcrição de Genes}

Um dos alvos conhecidos da CREB-1 nos processos neuronais de consolidação da LTF é uma região promotora chamada elemento responsivo ao AMPc (CRE) que promove a transcrição de genes como da enzima ubiquitina hidrolase e de outro fator de transcrição, a proteína C/EPB (do inglês, CCAAT-box-enhanced binding-protein) (JOSSELYN et al., 2002; KANDEL, 2002; 2012; LEE et al., 2008; SILVA et al., 1998). A ativação do CRE pela CREB é a chave de início para os eventos que culminarão na atividade persistente da subunidade catalítica da PKA e também para os mecanismos que providenciarão novas conexões sinápticas (HAWKINS et al., 2006).

Com a síntese da ubiquitina hidrolase promovida pela CREB-1, as subunidades catalíticas da PKA perdem suas subunidades regulatórias, passando a atuarem sem a necessidade de AMPc. Especificamente, a ubiquitina hidrolase é uma enzima protease que tem, como função, a clivagem proteolítica da subunidade regulatória da PKA, 
fazendo com que a subunidade com atividade enzimática atue de modo persistente (HAWKINS et al., 2006; KANDEL, 2002; 2012), prolongando ainda mais o influxo de cálcio pela fosforilação de canais iônicos e atuando em proteínas das vesículas sinápticas por mais tempo. O resultado final, portanto, é o prolongamento do tempo da plasticidade sináptica, que contribui para a formação da memória de longo prazo.

A outra molécula resultante da ação da CREB-1 é a C/EBP, um outro fator de transcrição (na verdade se trata de uma família de fatores transcricionais) com o poder de ativar a síntese de moléculas que irão participar da maquinaria de formação das novas conexões sinápticas da LTF (BAR et al., 1995; GUAN et al., 2002; LEE et al., 2008). Finalmente, o assunto agora se trata de alterações estruturais bruscas no neurônio, necessárias para que uma memória ultrapasse 24 horas de duração e se prolongue, inclusive, por semanas. No entanto, a CREB-1 e a C/ EBP não encerram os fatores de transcrição conhecidos. Estudos a respeito da memória usando a Aplysia revelaram mais uma molécula no transcorrer desses eventos, ou seja, o fator de ativação da Aplysia (ApAF), uma proteína com sítio de ligação para a C/EBP (BARTSCH et al., 2000; LEE et al., 2006). Quando ligadas, a C/EBP e a ApAF são capazes de ativar a transcrição de mais genes que participam da maquinaria de crescimento de novas conexões sinápticas. A ApAF, que é provavelmente ativada pelas enzimas PKA e PKC, também possui sítios de ligação para a CREB-2, com capacidade de desativá-la, agindo como uma agonista, juntamente a MAPK, para a livre ação da atividade de transcrição da CREB-1 (LEE et al., 2006).

Com a transcrição de RNA’s que carregam o código para síntese de proteínas da memória de longo prazo, outros mecanismos serão agora necessários para regular a tradução. Os RNA's mensageiros transcritos saem do núcleo rumo aos locais de crescimento de novos processos axonais. Uma vez no local requisitado, esses RNA's precisam ser ativados para a tradução, pois se encontram dormentes. Aqui surge mais um princípio para o desenvolvimento da LTF, pois ela precisa ser persistente nos neurônios e, para tanto, há mecanismos envolvidos na manutenção dessas novas conexões sinápticas estabelecidas. Surge, então, uma nova proteína, com características inéditas, chamada proteína ligadora da poliadenilação citoplasmática (CPEB) (COSTA-MATTIOLI et al., 2009; KANDEL, 2012). Por meio de uma atividade enzimática que alonga a cauda contendo poliadenilações do RNAm, a CPEB promove a ativação do RNA, permitindo sua tradução em locais específicos do neurônio no qual se dá a engenharia de novos processos sinápticos entre o neurônio sensório e o neurônio motor, aumentando suas interações.

Uma característica especial da CPEB chama a atenção: ela possui as propriedades de um príon (COSTA-MATTIOLI et al., 2009; HAWKINS et al., 2006; KANDEL, 2009; 2012). Isto é, se trata de uma proteína capaz de se autorreplicar, sem a necessidade de nova transcrição gênica, bastando, somente, que seja ativada nos sítios dos novos terminais sinápticos da LTF. Essa descoberta confere uma elegante explicação para a persistência da memória de longa duração, uma vez que a CPEB é capaz de fazer com o que os RNA's mensageiros envolvidos na manutenção da memória sejam continuamente traduzidos. Não se esperava encontrar príons que pudessem ter funções fisiológicas normais, pois são bem bem conhecidas as doenças como a encefalopatia espongiforme (HEINRICH; LINDQUIST, 2011) provocadas por príons. A CPEB encontrada na Aplysia se trata da primeira proteína priônica com funções fisiológicas descoberta (KANDEL, 2009) e seu desvendamento se deu por meio dos estudos relacionados aos mecanismos moleculares da memória.

\subsubsection{Mecanismos Pós-Transcricionais e Epigenética: Breves Considerações}

Resta agora saber quais mecanismos são responsáveis pelo transporte dos RNA's mensageiros até os terminais axônicos. O núcleo do neurônio se encontra significativamente distante dos terminais pré-sinápticos, tendo o RNA de percorrer um longo caminho pelo axônio. Além disso, se faz necessário o conhecimento dos mecanismos de marcação local, para que a mobilização da maquinaria de crescimento da nova conexão sináptica seja em região específica. Estudos a respeito desses dois âmbitos já possuem desenvolvimento, apesar de ainda carecer de explicações sólidas (SCHLAGER; HOOGENRAAD, 2009).

Outros estudos se concentram nos fatores epigenéticos envolvidos na formação da memória (HAWKINS; KANDEL; BAILEY, 2006; KANDEL, 2012; YU et al., 2011). Sabe-se que importantes mudanças ocorrem no material genético a partir do recrutamento de determinadas proteínas na formação da memória de longo prazo, uma dessas proteínas que possuem ação epigenética 
passa a agir a partir da já conhecida C/EBP (GUAN et al., 2002).

\section{Considerações finais}

É possível observar que as diferentes cascatas moleculares envolvidas na memória se intercruzam, agindo de tal modo que cada elemento envolvido nesse processo participa de vias simultâneas e correlacionadas. Logo, parece razoável pensar que a mutação de um único gene envolvido nesses processos seja o suficiente para manifestar problemas de memória ou, até mesmo, seja o caso de se ocasionar memórias excepcionais, se forem consideradas uma mutação que resulte na ausência ou deficiência de moléculas repressoras nesse mecanismo, tal como a CREB-2. Diversas outras ocasiões, ainda obscuras, aguardam explicações da neurociência molecular.

A maioria dos estudos apresentados possui como modelo o caramujo marinho Aplysia californica, apesar de existir também estudos com Drosophila e pequenos mamíferos. A escolha da Aplysia nesses estudos se deve a sua clara simplicidade neuronal. Seu sistema nervoso central possui, relativamente, poucas células $(20 \mathrm{mil}$ células). O circuito neuronal avaliado nos estudos de aprendizagem se restringe, apenas, a cem células. Essa simplicidade permite a investigação de mecanismos básicos que foram conservados durante a evolução das espécies, providenciando fundamentos que irão sustentar pesquisas com organismos superiores, tal como o homem.

Os estudos a respeito dos mecanismos básicos da memória permanecem em constante desenvolvimento. Já se conhece muitas das vias de segundos mensageiros e fatores de transcrição participantes. Contudo, outras vias, fatores e genes, ainda não estudados, aguardam elucidação. Assim, o esclarecimento a respeito dos processos básicos na aquisição de memória coincidirá com modelos de explicação mais sofisticados para mecanismos complexos como o da memória explícita de longo prazo, modalidade não exposta no presente trabalho, mas que possuem avançadas pesquisas em andamento. Nesse tipo de memória, em que os fatos ou lembranças são invocados à consciência, os estudos se baseiam em um evento que vem sendo abordado com uma frequência significativa: trata-se dos mecanismos envolvidos na potencialização levantam curiosidades constantes no meio neurocientífico, uma vez que a memória explícita é propriedade marcante da memória humana.

Há um longo caminho a percorrer para compreender os mecanismos que governam as funções mentais. A complexidade inerente desse campo de investigação pode ter tornado as pesquisas, durante tempos passados, pouco ambiciosas. Contudo, os primeiros passos, sobretudo acerca da memória, já foram dados. O substrato neural último da nossa mente pode então, finalmente, ser um objeto de estudo pensável: um fato que reservará grandioso empenho investigativo nos próximos anos.

\section{Referências}

BAR, D. et al. Aplysia CREB-2 represses long-term facilitation : relief of repression converts transient facilitation into long-term functional and structural change. Cell, Cambridge, v. 83, p. 979-992, 1995.

BARTSCH, D. et al. Enhancement of memory-related long-term facilitation by ApAF, a novel transcription factor that acts downstream from both CREB1 and CREB2. Cell, Cambridge, v. 103, n. 4, p. 595-608, 10 nov. 2000.

BLISS, T. V. P.; COLLINGRIDGE, G. L. Expression of NMDA receptor-dependent LTP in the hippocampus: bridging the divide. Molecular Brain, London, v. 6, p. 5, jan. 2013.

BLUM, A. L. et al. Short- and long-term memory in Drosophila require CAMP signaling in distinct neuron types. Current Biology: CB, Cambridge, v. 19, n. 16, p. 13411350, 25 ago. 2009.

BRANDÃO, M. L. As bases biológicas do comportamento: introdução à neurociência. São Paulo: EPU, 2004.

COSTA-MATTIOLI, M. et al. Translational control of long-lasting synaptic plasticity and memory. Neuron, Cambridge, v. 61, n. 1, p. 10-26, 15 jan. 2009.

DERIZIOTIS, P.; FISHER, S. E. Neurogenomics of speech and language disorders: the road ahead. Genome Biology, London, v. 14, n. 4, p. 204, 18 abr. 2013.

FAGHIHI, M. A. et al. Evidence for natural antisense transcript-mediated inhibition of microRNA function. Genome Biology, London, v. 11, n. 5, p. R56, jan. 2010.

GERITS, N. et al. Relations between the mitogen-activated protein kinase and the cAMP-dependent protein kinase pathways: comradeship and hostility. Cellular Signalling, Oxford, v. 20, n. 9, p. 1592-1607, set. 2008. 
GUAN, Z. et al. Integration of long-term-memory-related synaptic plasticity involves bidirectional regulation of gene expression and chromatin structure. Cell, Cambridge, v. 111, p. 483-493, 2002.

HAWKINS, R. D.; KANDEL, E. R.; BAILEY, C. H. Molecular mechanisms of memory storage in Aplysia. The Biological Bulletin, Chicago, v. 210, n. 3, p. 174-191, jun. 2006.

HEINRICH, S. U.; LINDQUIST, S. Protein-only mechanism induces self-perpetuating changes in the activity of neuronal Aplysia cytoplasmic polyadenylation element binding protein (CPEB). Proceedings of the National Academy of Sciences of the United States of America, Washington, v. 108, n. 7, p. 2999-3004, 15 fev. 2011.

HOOTEN, W. M. et al. Associations between serotonin transporter gene polymorphisms and heat pain perception in adults with chronic pain. BMC Medical Genetics, London, v. 14, n. 1, p. 78, jan. 2013.

IZQUIERDO, I. et al. Mecanismos da memória. Scientific American Brasil, São Paulo, n. 17, p. 99-104, 2003.

IZQUIERDO, I. et al. Different molecular cascades in different sites of the brain control memory consolidation. Trends in Neurosciences, Barking, v. 29, n. 9, p. 496-505, set. 2006.

JOSSELYN, S. A. et al. Long-term memory is facilitated by cAMP response element- binding protein overexpression in the amygdala. The Journal of Neuroscience, Washington, v. 21, n. 7, p. 2404-2412, 2001.

JOSSELYN, S. A. et al. CREB, plasticity and memory. 2002. Disponível em: <http://www.silvalab.com/silvapapers/CREBChapter2002.pdf>. Acesso em: 24 out. 2017.

KANDEL, E. R. The molecular biology of memory storage: a dialog between genes and synapses. Bioscience Reports, London, v. 24, n. 4-5, p. 475-522, 2002.

KANDEL, E. R. Em busca da memória: o nascimento de uma nova ciência da mente. São Paulo: Companhia das Letras, 2009.

KANDEL, E. R. The molecular biology of memory: CAMP, PKA, CRE, CREB-1, CREB-2, and CPEB. Molecular Brain, London, v. 5, n. 1, p. 14, jan. 2012.

KANDEL, E. R.; SCHWARTZ, J. H.; JESSELL, T. M. Princípios da neurociência. 4. ed. Barueri: Manole, 2003.

LASHLEY, K. S. In search of the engram. Cambridge University Press, 1950. (Nota técnica).
LEE, J.-A. et al. PKA-activated ApAF-ApC/EBP heterodimer is a key downstream effector of ApCREB and is necessary and sufficient for the consolidation of long-term facilitation. The Journal of Cell Biology, New York, v. 174 , n. 6 , p. $827-838,11$ set. 2006.

LEE, Y.-S. et al. Transcriptional regulation of long-term memory in the marine snail Aplysia. Molecular Brain, London, v. 1, p. 3, jan. 2008.

LEIDINGER, P. et al. A blood based 12-miRNA signature of Alzheimer disease patients. Genome Biology, London, v. 14, n. 7, p. R78, 29 jul. 2013.

LENT, R. Cem bilhões de neurôneos: conceitos fundamentais da neurociência. 2. ed. São Paulo: Atheneu, 2010.

MATSUDA, J. B. et al. Polimorfismos dos genes do receptor de serotonina ( COMT ): fatores desencadeantes da fibromialgia? Revista Brasileira de Reumatologia, São Paulo, v. 50, n. 2, p. 1-5, 2010.

MONTMINY, M. Transcriptional regulation by cyclic AMP. Annual Reviews of Biochemistry, Palo Alto, v. 66, p. $807-822,1997$.

MOURA, P. R. Transdução de sinais : uma revisão sobre proteína G. Scientia Medica, v. 21, n. 1, p. 31-36, 2011.

MOURA, R. B. L.; COSTA, C. A. S. C. Pode o ambiente influenciar nas funções neurobiológicas? Revista Eletrônica de Biologia, São Paulo, v. 5, n. 2, p. 9-12, 2012.

NESTLER, E.; MALENKA, R. Cérebro viciado. Scientific American Brasil, São Paulo, n. 18, p. 56-63, 2004.

ROBERSON, E. D. et al. The mitogen-activated protein kinase cascade couples PKA and PKC to cAMP response element binding protein phosphorylation in area CA1 of hippocampus. The Journal of neuroscience, Washington, v. 19, n. 11, p. 4337-4348, 1 jun. 1999.

RUSSO, J. A.; PONCIANO, E. L. T. O sujeito da neurociência: da naturalização do homem ao re-encantamento da natureza. Physis: Revista de Saúde Coletiva, Rio de Janeiro, v. 12, n. 2, p. 345-373, dez. 2002.

SÁ, C. S. C.; MEDALHA, C. C. Aprendizagem e memória: contexto motor. Revista Neurociências, São Paulo, v. 9, n. 3, p. 103-110, 2001.

SACKTOR, T. C. Memory maintenance by PKM evolutionary perspective. Molecular Brain, London, v. 5, n. 1, p. 31, jan. 2012. 
SAKAGUCHI, M.; HAYASHI, Y. Catching the engram: strategies to examine the memory trace. Molecular Brain, London, v. 5, p. 32, jan. 2012.

SANHUEZA, M.; LISMAN, J. The CaMKII/NMDAR complex as a molecular memory. Molecular Brain, London, v. 6, p. 10, jan. 2013.

SCHLAGER, M. A.; HOOGENRAAD, C. C. Basic mechanisms for recognition and transport of synaptic cargos. Molecular Brain, London, v. 2, p. 25, jan. 2009.

SHARMA, S. K.; CAREW, T. J. The roles of MAPK cascades in synaptic plasticity and memory in Aplysia: facilitatory effects and inhibitory constraints. Learning \& Memory (Cold Spring Harbor, N.Y.), Cold Spring Harbor, v. 11, n. 4, p. 373-378, 2004.

SILVA, A. J. et al. CREB and memory. Annual Reviews of Neuroscience, Palo Alto, v. 21, p. 127-148, 1998.

SKÅLHEGG, B. S.; TASKEN, K. Specificity in the cAMP/ PKA signaling pathway: differential expression, regulation, and subcellular localization of subunits of PKA. Frontiers in Bioscience, Tampa, v. 5, p. 678-693, 2000.
SQUIRE, L. R.; KANDEL, E. R. Memória: da mente às moléculas. Porto Alegre: Artmed, 2003.

SUTTON, M. A et al. Intermediate-term memory for site-specific sensitization in aplysia is maintained by persistent activation of protein kinase C. The Journal of neuroscience: the official journal of the Society for Neuroscience, Washington, v. 24, n. 14, p. 3600-3609, 7 abr. 2004.

SUTTON, M. A.; CAREW, T. J. Behavioral, cellular, and molecular analysis of memory in Aplysia I : Integrative and Comparative Biology, Oxford, v. 42, p. 725-735, 2002 .

THAKUR, P. et al. Effects of PKA-mediated phosphorylation of Snapin on synaptic transmission in cultured hippocampal neurons. The Journal of Neuroscience, Washington, v. 24, n. 29, p. 6476-6481, 21 jul. 2004.

TULLY, K.; BOLSHAKOV, V. Y. Emotional enhancement of memory: how norepinephrine enables synaptic plasticity. Molecular Brain, London, v. 3, p. 15, jan. 2010.

YU, N. K.; BAEK, S. H.; KAANG, B. K. DNA methylation-mediated control of learning and memory. Molecular Brain, London, v. 4, n. 1, p. 5, jan. 2011. 